\title{
Örgütsel Vatandaşlık Davranışının İş Performansı ve İşten Ayrılma Niyeti Üzerine Etkisinde Aşırı İş Yükünün Aracılık Rolü
}

\author{
The Mediating Role of Work Overload on the Effects of Organizational Citizenship \\ Behavior on Job Performance and Turnover Intention
}

\author{
Mazlum ÇELiK' ${ }^{1}$, Ahmet ÇIRA ${ }^{2}$
}

\begin{abstract}
ÖZET
Bu çalışmanın sorunsalı örgütsel vatandaşık davranışı (ÖVD) nın iş performansı ve işten ayrılma niyeti üzerine etkisi ile bu etkide aşııı iş yükünün aracılık rolü olup olmadığını araştırmaktır. Turizm sektöründe beş yıldızlı otel ve tatil köylerinde çalışanlar üzerinde yapılan araştırma sonucunda; ÖVD'nin iş performansını pozitif ve anlamlı etkilediği, aşııı iş yükü ve işten ayrılma niyetini negatif ve anlamlı etkilediği, aşııı iş yükünün iş performansını negatif, işten ayrılma niyetini pozitif yönde etkilediği belirlenmiştir. Ayrıca aşırı iş yükünün ÖVD ile iş performansı ilişkisine aracılık etmediği, ÖVD'nin işten ayrılma niyeti üzerine etkisine ise aracılık ettiği tespit edilmiştir. Aşırı iş yükünün aracılığına ilişkin bulguların literatüre katkı sağlayacağına inanılmaktadır.
\end{abstract}

Anahtar Kelimeler: Örgütsel vatandaşlık davranışı (ÖVD), iş performansı (IP), işten ayrılma niyeti (IAN), aşııı iş yükü (AiY).

\section{GíRiş}

Yüksek ve küresel rekabet ortamında işletmeler rakiplerine üstünlük sağlayarak ayakta kalma mücadelesi vermektedirler. Bu mücadelede başarılı olmanın en önemli şartlarından bir tanesi de, çalışanların güçlerinden ve yeteneklerinden azami fayda sağlayabilmektir. Bu kapsamda örgütsel vatandaşlık davranışı (ÖVD), çalışanların işletmeye olan katkılarının biçimsel rollerinin ötesine geçtiği önemli bir davranış biçimidir. Organ (1983), ÖVD'yi “biçimsel ödül sisteminde doğrudan ve tam olarak dikkate alınmayan, fakat bütün olarak örgütün fonksiyonlarını yerine getirmesine yardımcı olan, gönüllülüğe dayalı isteğe bağlı çalışan davranışları" olarak tanımlamaktadır.

Işten ayrılma niyeti, çalışanların örgütten ayrılma konusundaki bilinçli ve temkinli bir kararı veya eğilimi olarak tanımlanmaktadır (Bartlett, 1999: 70). İşletmelerde çalışanların sık sık işten ayrılmaları yani, işgücü değişim hızının yüksek olması önemli sıkıntılara sebep olabilmektedir (Demir ve Tütüncü, 2010:67).

\section{ABSTACT}

The problematic of this study to investigate the effect of organizational citizenship behavior (OCB) on job performance and turnover intention and mediating role of work overload in this effect. It is determined as a result of the study conducted on the employees working in five-star hotels and first-class holiday villages that the $\mathrm{OCB}$ affect on job performance positive and significant, on turnover intention and work overload negative and significant; work overload has effects on job performance negative and significant, on turnover intention positive and significant. Additionally it is defined that the work overload has no mediation effect between $O C B$ and job performance and partial mediation effect between the OCB and turnover intention. It is believed that the findings to the moderation of work overload contribute to literature.

Keywords: Organizational Citizenship Behavior (OCB), job performance, turnover intention, work overload.

Bu nedenle özellikle kalifiye çalışanların uzun süreli olarak çalışmaya devam etmeleri arzu edilmektedir. Zira, örgütte sosyalleşen, belli performans seviyesine ulaşan çalışanların işletmeden ayrılmaları eğitim, oryantasyon ve düşük performanstan kaynaklanan maliyetlere sebep olabileceği düşünülmektedir. Çalışanların işten ayrılma niyetlerini etkileyen faktörlerden birisi de aşırı iş yüküdür (Jones vd., 2007: 664-665). Aşırı iş yükü, çalışanların fazlaca yüklendiği roller olarak tanımlanmakta ve uzun zaman çalışmayı, ezici ve zorlayı görevleri kapsadığı ifade edilmektedir (Greenhaus vd., 1989). Elloy ve Smith (2003); aşırı iş yükünün nitel olarak işten gelen taleplerin ya da görevlerin çok zor olması ile ortaya çıkarken, nicel olarak aşırı iş yükünün bireyin birden çok farklı görevi yapması gerekirken, bunları, yerine getirememesinden kaynaklandığını belirtmektedir (Derya, 2008:14).

Bu çalışmanın sorunsalı turizm sektöründe çalışanların sergiledikleri ÖVD'nin iş performansları ve işten ayrılma niyetleri üzerine etkisinde aşırı iş yükünün aracılık rolünün olup olmadığının ortaya konul- 
masıdır. Araştırma sonucunda elde edilen bulguların özellikle sergilenen ÖVD'nin de bir sınırının olması gerektiği ve belli bir seviyenin üzerine çıktığında arzu edilenlerden farklı sonuçların da ortaya çıkabileceği konusunda literatüre ve uygulamaya katkı sağlayacağına inanılmaktadır. Ayrıca araştırmanın her geçen gün gelişen ve Dünyadaki rakipleri ile rekabet eden ve önemli kısmı sözleşmeli (mevsimlik) olan turizm sektörü çalışanları üzerinde yapılmasının hem turizm sektörü hem de benzer istihdam politikaları izleyen işletmeler açısından önemli sonuçlar vereceği düşünülmektedir.

\section{TEORI VE HIPOTEZLER}

Kökenleri Barnard (1938)'ın araştırmalarına kadar uzanan Örgütsel Vatandaşlık Davranışı (ÖVD), esas olarak Organ ve arkadaşları (Bateman ve Organ, 1983) tarafından yapılan çalışmalar sonucunda literatüre kazandırılmıştır. Organ, ÖVD'yi “biçimsel ödül sisteminde doğrudan ve tam olarak dikkate alınmayan, fakat bütün olarak örgütün fonksiyonlarını yerine getirmesine yardımcı olan, gönüllülüğe dayalı isteğe bağlı çalışan davranışları" olarak tanımlamıştır. Podsakoff ve arkadaşları (2000:513) ise, ÖVD'yi "görev ve iş tanımlarında yer almayan, ihmali halinde ceza gerektirmeyen ve daha çok kişisel tercih sonucu sergilenen davranışlar" olarak tanımlamışlardır. Her iki tanımda da ÖVD'nin örgütün ceza ve ödül sisteminden etkilenmeyen, gönüllülüğe dayalı ve örgütün faydasına olan davranışlar olduğu vurgulanmıştır.

Organ (1988), "iyi asker sendromu" olarak tarif ettiği ÖVD'yi, diğergamlık (altruism), üstün görev bilinci (conscientiousness), nezaket (courtesy), sivil erdem (civic virtue) ve centilmenlik (Sportsmanship) olmak üzere beş boyutta incelemiştir. Diğergamlık, çalışanların kendi işlerine ilave olarak işle ilgili problemlerde diğer çalışanlara gönüllü olarak yardım etme, işe yeni başlayanların sosyalleşme süreçlerine katkı sağlama, işe gelmeyen veya işini yetiştiremeyen arkadaşlarına destek sağlama gibi iş arkadaşlarına odaklı yardımlaşma davranışıdır (Organ, 1988, 1990a, 1990b: 96, Podsakoff vd., 2000:518). Bazı araştırmalarda "vicdanlılık" olarak da geçen üstün görev bilinci, kimse takip etmese bile kurallara uyma, işe zamanında gelme, molaları zamanında bitirme, biçimsel rollerinin ötesinde performans gösterme gibi örgüt odaklı yardımlaşma davranışlarıdır(Redman ve Snape, 2005). Nezaket ise, çalışma arkadaşlarını ortaya çıkabilecek problemler konusunda önceden ikaz etme, onları bilgilendirme gibi çalışan davranışlarıdır (Organ, 1988, 1990a, 1990b:96; Podsakoff vd., 2000:
518). Çalışanların örgütü etkileyebilecek olaylara karşı kendilerini sorumlu kılmaları, alınan kararlara gönüllü olarak katılmaları, toplantılara iştirak etmeleri sivil erdem boyutu kapsamında olan davranışlardır (Schnake ve Dumler, 1993:352). Centilmenlik ise, örgüt içerisindeki olumsuzluklardan şikayetçi olmama, tolerans gösterme, işle ilgili her türlü faaliyeti sızlanmadan ve şikayetçi olmadan yerine getirme davranışlarıdır(Organ, 1988, 1990a, 1990b:96; Podsakoff vd., 2000:518).

Çalışanların sergiledikleri ÖVD'nin sebepleri, genellikle Sosyal Değişim Teorisi (Blau,1964) ve Karşılıklılık Normu (Gouldner,1960) ile açıklanmaktadır. Örgüt ile tanımlanmış rol gereklerini yerine getirme karşılığında ekonomik değişime dayanan biçimsel sözleşme imzalayan çalışanlar, ayrıca gönüllerinde de "psikolojik sözleşme" olarak isimlendirilen bir sözleşme imzalamaktadır. Sosyal değişimi esas alan bu sözleşmeye göre çalışanlar, kendilerine iyi ve adil davranılmasını, zor günlerinde yöneticileri tarafından korunup kollanmalarını beklemektedir. Beklentileri karşılanan ve iyilik gören çalışanların, karşılıklılık ilkesi gereği gönüllü olarak örgütün faydasına olacak rol ötesi davranışlar sergileyeceğine inanılmaktadır.

ÖVD, çalışanlar tarafından gönüllü olarak sergilendiğinden genellikle çalışanlar (yüksek iş tatmini, düşük iş stresi, düşük işten ayrılma niyeti vb.) ve örgüt üzerinde (yüksek performans, düşük iş devamsızlığı, düşük çatışma seviyesi) olumlu etkiler sağlayacağı düşünülmektedir. Yapılan araştırma bulgularının önemli bir kısmı da bu düşünceyi desteklemektedir. Özellikle ÖVD'nin performans üzerinde olumlu etkileri olduğuna ilişkin bulguları olan çok fazla araştırma bulunmaktadır (Bateman ve Organ, 1983; Borman ve Motowidlo, 1997; Williams ve Anderson, 1991; Netemeyer vd., 1997; Ozdeveicoğlu, 2003: 118; MacKenzie vd., 1993; Organ, 1988; Kamer, 2001:22). Zaten çalışanların örgütün faydasına olacak şekilde kendi biçimsel rollerinin ötesinde faaliyetler gerçekleştirmelerinin performansı olumlu etkileyeceği mantıkı bir beklentidir (Borman ve Motowidlo, 1993).

ÖVD'nin performans üzerindeki en önemli etkisinin takım içi işbirliği ve uyumunu artırması yoluyla gerçekleştiği düşünülmektedir (Bateman ve Organ, 1983; Nielsen vd., 2010: 2). Gönüllü olarak sergilenen yardımlaşmaya ve fedakârlığa dönük davranışların, örgütün sosyal mekanizmasının işlerliğini artırdığı, anlaşmazlıkları azalttığı ve etkinliği yükselttiği için örgüt performansı üzerinde olumlu etki yaptığı ileri sürülmektedir (Organ, 1988). 
Literatürdeki farklı örneklemler üzerinde yapılan birçok görgül araştırma sonucunda, ÖVD ile iş performansı arasında pozitif yönde ilişki tespit edilmiştir. Örneğin; Özdevecioğlu (2003: 129) tarafından üniversite öğrencileri üzerinde, Rosen ve arkadaşları (2009:39) tarafından aile hekimleri üzerinde, Allen ve Rush (1998) tarafından yöneticilik kursiyerleri üzerinde, Borman ve arkadaşları (1995) tarafından askeri personel üzerinde, Lowery ve Krilowicz (1994) tarafından mavi yakalılar üzerinde yapılan araştırmaların sonucunda ÖVD ile performans arasında olumlu ilişkiler belirlenmiştir.

Kuramsal çerçeve ve yapılan görgül araştırmalara dayanılarak ÖVD iş performansı arasındaki ilişkiye yönelik aşağıdaki hipotez ortaya konulmuştur.

$\mathrm{H}_{1}$ : ÖVD çalışan performansını pozitif ve anlamlı olarak etkiler.

ÖVD'nin olumlu sonuçlarından birisi de çalışanların işten ayrılma niyetlerini düşürmesidir (Chughtai ve Zafar, 2006; Khalid ve Ali, 2005; Podsakoff ve Mackenzie, 1997). Organ (1988)'a göre ÖVD, çalışılan örgüt ortamını cazip bir hale getirerek örgüte nitelikli işgücünü çekme ve elinde tutma yeteneğini sağlamaktadır (Kamer, 2001:22). Podsakoff ve arkadaşları (2000: 544-545) da ÖVD'nin kaliteli işgücü için örgütü cazip hale getirdiğini ve örgütte kalmalarına katkı sağladığını belirtmişlerdir.

Literatür incelendiği zaman, ÖVD ve işten ayrılma niyeti arasında negatif ilişki olduğunu gösteren birçok çalışmanın mevcut olduğu görülmektedir. Nadiri ve Tanova (2010:36) tarafından beş yıldızı ıtel çalışanları üzerinde; Felfe arkadaşları (2008:227) tarafından farklı kültürlerde (Almanya, Romanya ve Çin) olmak üzere hava yolu, otel ve telekomünikasyon çaıışanları üzerinde; Rosen ve arkadaşları (2009:39) aile hekimleri üzerinde; Byrne (2005) tarafından hemşire, teknisyen ve tedavi uzmanı vb. hastane çalışanları üzerinde; Suazo ve arkadaşları (2005:32) tarafından kamuda çalışan beyaz yakalı çalışanları üzerinde; Wegge ve arkadaşları (2006:68) tarafından çağrı merkezi çalışanları üzerinde ve Bellou (2008:783) tarafından restoran çalışanları üzerinde yapılan çalışmaların tamamında ÖVD ile işten ayrılma niyeti arasında negatif ve anlamlı bir ilişki belirlenmiştir.

Kuramsal çerçeve ve yapılan görgül araştırmalara dayanılarak ÖVD ile işten ayrılma niyeti arasındaki ilişkiye yönelik aşağıdaki hipotez ortaya konulmuştur.

$\mathrm{H}_{2}$ : ÖVD işten ayrılma niyetini negatif ve anlamlı olarak etkiler.
Tüm olumlu sonuçlarına rağmen ÖVD'nin onu sergileyen çalışanlar açısından olduğu kadar, iş gruplarındaki arkadaşlar ve örgüt etkinliği açısından da bazı olumsuz sonuçlarının olabileceği yeni de olsa kabul gören bir yaklaşımdır (Spitzmuller vd., 2008:117). Bunlardan birisi de aşırı iş yüküdür (Spector vd., 2002:55). ÖVD’nin özellikle "diğergamlık, üstün görev bilinci ve sivil erdem boyutlarının" aşırı iş yükü ile pozitif ilişki içerisinde olması beklenmektedir (Bolino ve Turnley, 2005'den aktaran Fox ve Spetor, 2009:22). Bolino ve Turnley (2005:740), Organ ve Ryan (1995)'a dayanarak örgütte iyi bir vatandaş olmanın, çalışanda strese ve aşırı iş yüküne neden olabileceğini ifade etmişlerdir. Mesai saatlerinden sonra çalışma, kendi görevleri yanında arkadaşlarının da işlerine destek sağlama, dinlenme zamanlarında örgüt için eğitim, toplantı ve seyahatlere katılmanın birer ÖVD olduğu düşünüldüğünde, Bolino ve Turnley (2005:740)'e hak vermemek mümkün görünmemektedir (Bolino vd., 2004:241).

ÖVD ile aşırı iş yüklenmesi arasında pozitif ve anlamlı bir ilişki olduğunu doğrulayan çok az görgül çalışmadan birisi Spector ve arkadaşları (2002:54) tarafından yapılmıştır. Bu araştırmada; üretim, finans, akademik gibi değişik meslek gruplarında çaIışan toplam 203 çalışan üzerinde yapılan araştırma sonucunda; ÖVD ile aşrı iş yükü arasında pozitif ve anlamlı bir ilişki belirlenmiştir. Aynı şekilde Organ ve Ryan (1995) tarafından farklı üniversitelerin mezunları üzerinde yapılan araştırmada, kişisel inisiyatif ile aşırı iş yükü arasında pozitif ve anlamlı ilişki olduğu görülmüştür. Singh ve Singh (2008:52) tarafından Hindistan'da 82 kamu kurumu ve 48 özel sektör kuruluşunda çalışan 130 yöneticiye yönelik olarak yapılan araştırmanın sonuçları da, ÖVD' nin aşırı iş yüküne sebep olabileceği yönündedir.

Dayanma gücü ve kapasitelerinin üzerindeki aşırı iş yükü nedeniyle yüksek stres ve tükenmişlik yaşayan çalışanların iş ortamında mutlu olamayacakları, işlerinden zevk alamayacakları ve dolayısıyla performanslarında düşüş olabileceği, fırsat ortaya çıktığında işlerinden ayrılmayı isteyebilecekleri düşünülmektedir. Bir stres kaynağı olarak değerlendirilen aşırı iş yükünün, iş stresi, aile iş çatışması (Luk ve Shaffer,2005; Derya, 2008: 15), devamsızlık, düşük performans, düşük iş tatmini ve yüksek işten ayrılma isteğine (Jones vd., 2007: 664-665;Golden ve Jorgensen, 2002:3) sebep olduğuna yönelik araştırma bulguları vardır. Schepman ve Zarate (2008) tarafından hizmet sektöründe yapılan araştırmada, ÖVD' nin alt boyutlarından olan özgecilik ile tükenmişlik duygusu arasında pozitif yönde ve kuvvetli bir ilişki belirlenmiştir. Cropanzano ve Byrne (2005) 
tarafından 204 sağlık çalışanı üzerinde yapılan araştırmada, duygusal yorgunluk ile işten ayrılma isteği arasında pozitif yönde kuvvetli bir ilişki tespit edilmiştir. Sonuç olarak, aşırı iş yükünün iş performansı ve işten ayrılma niyeti üzerinde olumsuz etkileri olabileceği ve ÖVD ile iş performansı ve işten ayrılma niyeti arasında aracılık etkisi yapabileceği düşünülmektedir.

Kuramsal çerçeve ve yapılan görgül araştırmalara dayanılarak aşağıdaki hipotezler ortaya konulmuştur.

$\mathrm{H}_{3}$ : ÖVD aşırı iş yükünü pozitif ve anlamlı olarak etkiler.

$\mathrm{H}_{4}$ : Aşırı iş yükü iş performansını negatif ve anlamlı olarak etkiler.

$H_{5}$ : Aşırı iş yükü işten ayrılma niyetini pozitif ve anlamlı olarak etkiler.

$\mathrm{H}_{6}$ : ÖVD'nin iş performansı üzerine etkisinde aşırı iş yükünün aracılık rolü vardır.

$\mathrm{H}_{7}$ : ÖVD'nin işten ayrılma niyeti üzerine etkisinde aşırı iş yükünün aracılık rolü vardır.

\section{ARAŞTIRMANIN YÖNTEMI}

Örgütsel Vatandaşık Davranışı (ÖVD)nın iş performansı (IP) ve işten ayrılma niyeti (IAN) üzerine etkisinde aşırı iş yükünün aracılık etkisini araştırmaya yönelik bu araştırmada, öncelikle örneklem ve ölçeklere ilişkin bilgilere yer verilmiştir. Ardından örneklemden elde edilen veriler doğrultusunda oluşturulan modele ilişkin analizler yapılmıştır. Bu kapsamda, öncelikle her bir değişkenin doğrulayıcı faktör analizi yapılmış, ardından değişkenler arası korelasyonlar tespit edilmiştir. Bağımsız değişkenlerin bağımlı değişkenler üzerine etkileri ile AiY'nin aracılık rolünü belirlemek amacıyla hiyerarşik regresyon analizleri ve Sobel testleri yapılmıştır Tüm bu analizler sonucunda elde edilen bulgular, mevcut literatür ile karşılaştırılarak yönetici ve araştırmacılara önerilerde bulunulmuştur. Kuramdan ve görgül araştırmalardan yola çıkılarak oluşturulan araştırma modeli ve hipotezler Şekil 1' de sunulmuştur.

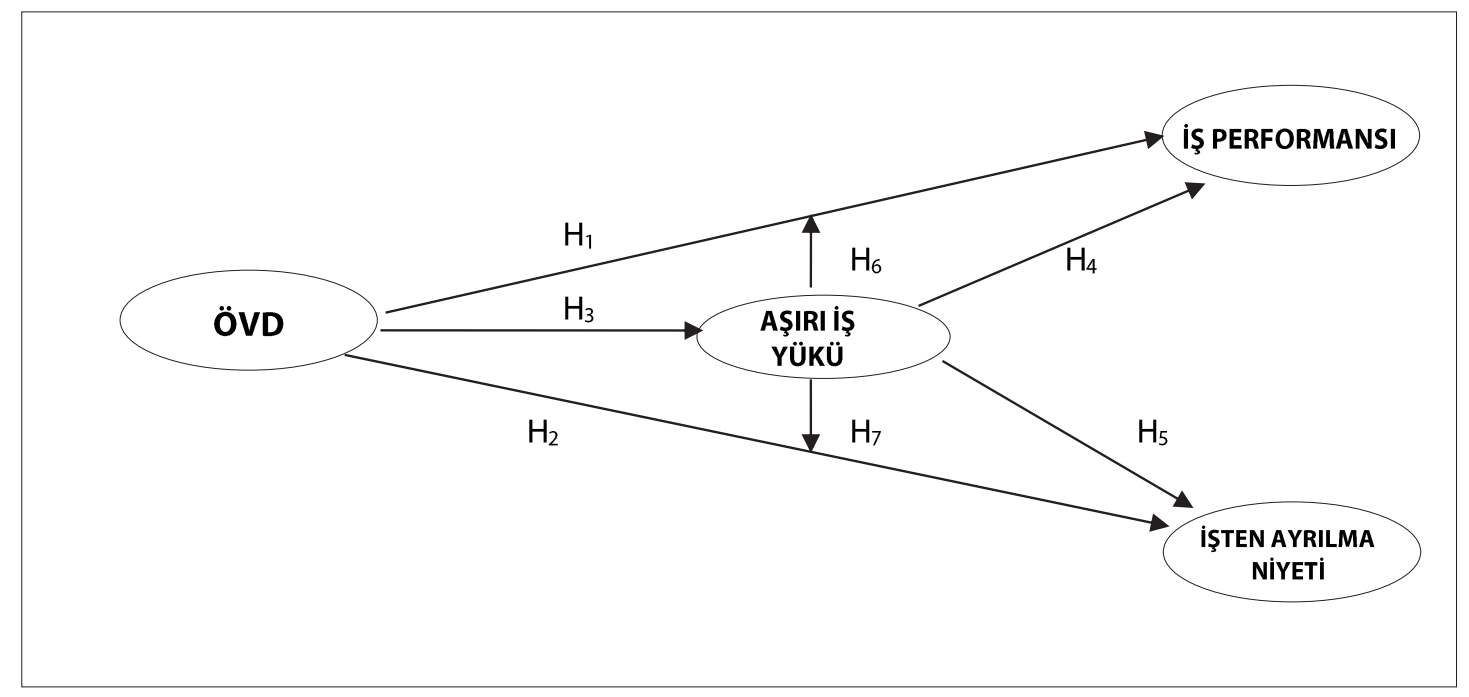

Şekil 1: Araştırma Modeli ve Hipotezler

\subsection{Araştırmanın Örneklemi}

Araştırmanın evrenini; Antalya'nın Kemer ilçesinde, turizm sektöründe faaliyet gösteren beş yıldızlı otellerde ve birinci sınıf tatil köylerinde, yaz döneminde çalışan yaklaşık 50.000 işgören oluşturmaktadır. Araştırmanın örneklemini ise, bu bölgede faaliyet gösteren beş farklı "beş yıldızlı otel ve tatil köyü" çaIışanlarından 432 işgören oluşturmaktadır. Araştırmada, bu işletmelerde görev yapan 550 personelden "anket yöntemi" ile toplanan veriler kullanılmıştır. Katılımcılara gönderilen anketlerin 482 adedi geri alınmıştır. Analizler öncesi kayıp veri ve temel değişkenler üzerinden yapılan incelemeler sonucunda, 50 kişiye ait veriler analizden çıkarılmış, analizlere 432 kişilik bir örneklem üzerinden devam edilmiştir. Araştırmaya katılan toplam 432 katılımcıdan kadınların sayısı $135(\% 3,3)$, erkeklerin sayısı $297(\% 68,8)$ 'dir. Katılımcılardan 166 kişi (\%38) 25- 34 yaş grubunda, 157 kişi (\%36) 15- 24 yaş grubundandır. 300 kişi (\%70) 1-5 yıl, 91 kişi (\%21) 6-10 yıl bu kurumda çalıştıklarını belirtmişlerdir. Evli olanların sayısı 206 (\%48), bekârların sayısı 226 (\% 52)'dır. Kadrolu çalışan sayısı 101 (\%23) iken, sözleşmeli çalışan sayısı 331 (\%77)'dir. Eğitim durumlarına bakıldığı zaman ise, çalışanlardan 169 kişinin (\%40) lise mezunu, 95 kişinin ilkokul (\%22), 85 kişinin ise ortaokul (\%20) mezunu olduğu görülmektedir. 


\subsection{Araştırmanın Ölçekleri}

Araştırmada kullanılan ölçeklere ilişkin bilgiler aşağıda sunulmuştur. Kullanılan tüm ölçeklerin daha önce kullanılmış olmaları ve güvenilirlik ve geçerliliklerinin de kanıtlanmış olması nedeni ile öncelikle ölçeklere ait faktör yapılarını doğrulamak maksadıyla AMOS programında doğrulayıcı faktör analizi (DFA) yapılmıştır. Ölçeklere ait doğrulayıcı faktör analizi sonuçları Tablo-1'de verilmiştir.

ÖVD Ölçeği: Çalışanların sergiledikleri ÖVD'yi ölçmek için, ÖVD'yi beş boyutu ile ölçen ve Şeşen (2006) tarafından Vey ve Campbell (2004) ile Williams ve Shiaw (1999) tarafından kullanılan ölçeklerden faydalanılarak Türk kültürüne ve Türkçe'ye uyarlama çalışmaları yapılmış olan beş boyutlu 19 maddeli (Günlük izin alan bir personel isterse, o günkü işlerini ben yapabilirim) ÖVD ölçeği kullanılmıştır.

Bu çalışmada ankette sorulan faktörlerin açıkladığı toplam varyans $\% 65$, ölçeğin toplam güvenirliği ise (Cronbach a) 0,91 olarak hesaplanmıştır. Mevcut çalışmada ÖVD ölçeği için yapılan doğrulayıcı faktör analizinde "ikinci düzey çok faktörlü yapı" diğer tüm modellerden daha yüksek uyum iyiliği göstermiştir (Tablo-1). Bu nedenle önce beş boyut olarak ele alınan ÖVD ölçeği DFA sonucunda tek faktör altında (Genel ÖVD) toplanmış ve korelâsyon ve regresyon analizlerinde tek boyutlu olarak kullanılmıştır. Bu modele göre 19 maddeden herhangi bir madde çıkarılmamıştır. Uyum iyileştirmeleri sonucu tek faktörlü olarak ele alınmaya karar verilen Genel ÖVD'nin açıkladığı toplam varyans $\% 41,66$, ölçeğin güvenilirlik katsayısı (Cronbach a) ise 0,91 olarak gerçekleşmiştir. Ölçeğin Keiser-Meyer- Olkin analiz sonucu 0,95 ve Barlett testi anlamlı $(p=.000)$ olarak tespit edilmiştir.

Aşırı İş Yükü Ölçeği: Çalışanların içinde bulundukları aşırı iş yükünü ölçmek için, Peterson ve arkadaşları (1995) tarafından geliştirilen ve Derya (2008) tarafından Türk Kültürüne uyarlanan 11 maddeli (İşimde benden talep edilenler kapasitemin üstündedir.) aşırı iş yükü ölçeği kullanılmıştır. Mevcut çalışmada, aşırı iş yükü ölçeğinin açıkladığı tek faktörlü toplam varyans $\% 34,77$, ölçeğin güvenilirlik katsayısı (Cronbach a) ise 0,79 olarak gerçekleşmiştir. Ölçeğin Keiser-Meyer- Olkin analiz sonucu 0,81 ve Barlett testi anlamlı $(p=.000)$ olarak tespit edilmiştir.

İş Performansı Ölçeği: Çalışanların iş performansının ölçülmesinde; önce Kirkman ve Rosen (1999), daha sonra ise, Sigler ve Pearson (2000) tarafından kullanılan iş performansı ölçeği kullanılmıştır. Dört sorudan oluşan ( Görevlerimi zamanında tamamla- rım.) ölçeğin güvenirlik katsayısı her iki çalışmada da 0.70'in üstündedir. Türkiye'de Çöl (2008) tarafından akademisyenler üzerinde uygulanan ölçeğin güvenirlik katsayısı Cronbach $a=.82$ olarak tespit edilmiştir. Araştırmada cevaplar 5'li Likert ölçeği ile alınmıştır (1=Kesinlikle katılmıyorum, 5=Kesinlikle katılıyorum).

Mevcut çalışmada, iş performansı ölçeğinin açıkladığı tek faktörlü toplam varyans \% 57,19, ölçeğin güvenilirlik katsayısı (Cronbach a) ise 0,75 olarak gerçekleşmiştir. Ölçeğin Keiser-Meyer- Olkin analiz sonucu 0,75 ve Barlett testi anlamlı $(p=.000)$ olarak tespit edilmiştir.

İşten Ayrılma Niyeti Ölçeği: Çalışanların işten ayrılma niyetini ölçmek için, Walsh, Ashford ve Hill (1985) tarafından geliştirilen ve güvenilirlik katsayısı Cronbach $a=0.81$ olarak belirlenen beş maddeli (Sık sık bu işten ayrılmayı düşünürüm.) işten ayrılma niyeti ölçeği kullanılmıştır. Ok (2004) tarafından Türkçe' ye uyarlanan ölçeğin güvenilirlik katsayısı yine Cronbach $\alpha=0.81$ olarak gerçekleşmiştir.

Mevcut çalışmada işten ayrılma niyeti ölçeğinin açıkladığı tek faktörlü toplam varyans \% 57,59, ölçeğin güvenilirlik katsayısı (Cronbach a) ise 0,81 olarak gerçekleşmiştir. Ölçeğin Keiser-Meyer- Olkin analiz sonucu 0,78 ve Barlett testi anlamlı $(p=.000)$ olarak tespit edilmiştir.

\subsection{Bulgular}

Araştırma sonucunda elde edilen verilere SPSS ve Amos programında analizler yapılmıştır. Bu kapsamda, ilk aşamada araştırmada kullanılan ölçeklerin doğrulayıcı faktör analizleri(DFA) yapılmış ve sonuçların kabul edilebilir sınırlar içerisinde olduğu görülmüştür. DFA sonuçları Tablo 1' de toplu halde sunulmuştur.

Tablo 1: Tüm Ölçeklerin Doğrulayıcı Faktör Analizlerine Yönelik Uyum Iyiliği Değerleri

\begin{tabular}{|c|c|c|c|c|c|c|c|}
\hline \multicolumn{1}{|c|}{ Analizlerine Yönelik Uyum lyiliği Değerleri } \\
\hline ÖLÇEK & $\Delta x^{2}$ & sd & $\Delta x^{2} /$ sd & RMSEA & CFI & GFI & AGFI \\
\hline ÖVD & 418,30 & 139 & 3,00 & 0,07 & 0,92 & 0,91 & 0,87 \\
\hline AIY & 102,15 & 30 & 3,40 & 0,07 & 0,91 & 0,95 & 0,92 \\
\hline IP & 6,225 & 2 & 3,112 & 0,07 & 0,98 & 0,99 & 0,96 \\
\hline IAN & $5,579 *$ & 3 & 1,860 & 0,045 & 0,99 & 0,99 & 0,97 \\
\hline
\end{tabular}

Not: RMSEA = Root Mean Square Error of Approximation

$\mathrm{CFI}=$ Comparative Fit Index; GFI= Goodness of Fit Index;

$\mathrm{AGFI}=$ Adjusted of Goodness Fit Index, sd= Serbestlik Derecesi, * $\mathrm{p}>0,05$

İkinci aşamada ise ÖVD, AIY, IAN ve IP'ye ilişkin elde edilen verilerin ortalamaları, standart sapmaları ve aralarındaki korelasyonlara bakılmıştır. Bulgular Tablo 2'de sunulmuştur. 
Tablo 2: Araştırmanın Değişkenlerine Ait Ortalama, Standart Sapma, Korelâsyon Değerleri ve Ölçeklere ait Güvenilirlikler

\begin{tabular}{|l|c|c|c|c|c|c|}
\hline Değişkenler & Ort. & S.S. & 1 & 2 & 3 & 4 \\
\hline 1. ÖVD & 4,57 & 0,94 & $(0,91)$ & & & \\
\hline 2. AiY & 2,98 & 0,76 &,$- 150^{* *}$ & $(0,79)$ & & \\
\hline 3. IP & 4,10 & 0,71 &, $467^{* * *}$ &,$- 098^{*}$ & $(0,75)$ & \\
\hline 4. IAN & 2,80 & 0,96 &,$- 305^{* * *}$ &, $450^{* * *}$ &,$- 185^{* * *}$ & $(0,81)$ \\
\hline
\end{tabular}

${ }^{*} p<0,05,{ }^{* *} p<0,01,{ }^{* * *} p<0,001,(a)$

Tablo 2 'de de görüldüğü gibi araştırmaya konu edilen tüm bağımlı ve bağımsız değişkenler arasında anlamlı ilişkiler bulunmaktadır. Bu nedenle değişkenler arasında önemli etkiler öngörülebilmektedir.

Analiz kapsamında modelde çoklu doğrusal bağlantı sorunu olup olmadığını belirlemek maksadıyla doğrudaşlığa (collinearity) da bakılmıştır. Elde edilen tolerans ve VIF değerleri bağımsız değişkenler arası çoklu bağlantı olmadığını doğrulayan sonuçlar vermiştir (Tolerans > .23, VIF< 10).

ÖVD'nin IP ve İAN üzerine etkisini ve bu etkide AiY'nin aracılık rolünü açıklamak amacıyla, Baron ve Kenny (1986) tarafından önerilen üç aşamalı regresyon analizi yapılmıştır. Bu yönteme göre, bağımsız değişkenin bağımlı değişken ve aracı değişken üzerinde bir etkisi olmalıdır. Aracı değişken bağımsız değişkenle birlikte regresyon analizine dâhil edildiğinde, bağımsız değişkenin bağımlı değişken üzerindeki regresyon katsayısı düşerken, aracı değişkenin de bağımlı değişken (IP ve IAN) üzerinde anlamlı etkisi sürmelidir. Bu kapsamda AiY'nin aracılık rolünü belirlemek amacıyla hiyerarşik regresyon analizleri ve Sobel testleri yapılmıştır. Aracılık testine ilişkin bulgular Tablo 3 ve 4 'te verilmektedir.

ÖVD'nin IP üzerine etkisinde AiY'nin aracılı̆̆ını test etmek maksadıyla yapılan üç aşamalı hiyerarşik regresyon analizi sonucunda (Tablo-3) ÖVD'nin IP'yi $(\beta=0,467 ; p<, 001)$ pozitif ve anlamlı olarak etkilediği görülmüştür. İkinci adımda ÖVD'nin aracılığı araştırıIan AiY' ye olan etkisi araştırılmıştır. Analiz sonucunda ÖVD'nin AiY' de negatif ve anlamlı olarak etkilediği $(\beta=-0,150 ; p<, 01)$ tespit edilmiştir. Bu adımda aracılığı araştırılan AiY'nin IP' ye olan etkilerine de bakılarak Tablo-3'te rapor edilmiştir $(\beta=-, 098 ; p<, 01)$ . Son adımda ise ÖVD ve aracılığı araştııılan AiY birlikte analize sokulmuş ve IP üzerindeki etkilerine bakılmıştır. Analiz sonucunda, ÖVD'nin AiY ile birlikte analize sokulmasıyla $R 2$ artmış $(\triangle R 2=0,001)$ ve ilk aşamada var olan ÖVD'nin IP üzerindeki etkisi azalmıştır $(\beta=0,463 ; p<, 001)$. Fakat Sobel testi sonuçları aracılık etkisinin anlamlı olmadığını göstermektedir $(z=1,92 ; p>0,05)$. Bu bulgular ÖVD'nin IP'ye etkisinde AíY' nin aracılık rolünün olmadığını göstermektedir (Tablo-3).Bu analiz sonucunda $\mathrm{H} 1$ ve $\mathrm{H} 4$ desteklenmiş, $\mathrm{H} 3$ ve $\mathrm{H} 6$ ise destek bulmamıştır.

Tablo 3: Aşırı Iş Yükünün ÖVD- İş Performansı Arasında Aracılık Rolünü Gösteren Hiyerarşik Regresyon Sonuçları

\begin{tabular}{|c|c|c|}
\hline \multicolumn{3}{|c|}{ İS PERFORMANSI } \\
\hline \multicolumn{3}{|c|}{ Test 1- İş Performansı } \\
\hline & $\beta$ & $\mathrm{t}$ \\
\hline ÖVD & $0,467^{* * *}$ & 10,94 \\
\hline \multicolumn{3}{|c|}{$R^{2}=0,21$ Düz. $R^{2}=0,21 \quad F=119,84 p(F) 0,000$} \\
\hline \multicolumn{3}{|c|}{ Test 2- Aşırı İş Yükü } \\
\hline & $\beta$ & $\mathrm{t}$ \\
\hline ÖVD & $-0,150^{* *}$ & $-3,15$ \\
\hline \multicolumn{3}{|c|}{$\begin{array}{l}R^{2}=0,02 \text { Düz. } R^{2}=0,02 \quad F=9,92 p(F) 0,002 \\
\text { AiY } \rightarrow \text { IP } \beta=-.098^{*} \quad R^{2}=.01\end{array}$} \\
\hline \multicolumn{3}{|c|}{ Test 3- Iş Performansı } \\
\hline & $\beta$ & $\mathrm{T}$ \\
\hline ÖVD & $0,463^{* * *}$ & 10,71 \\
\hline Aşırı İş Yükü & $-0,028$ & $-0,654$ \\
\hline \multicolumn{3}{|c|}{$\begin{array}{c}R^{2}=0,219 \text { Düz. } R^{2}=0,215 \\
\Delta R^{2}=0,001 F=60,05 p(F)=0,000\end{array}$} \\
\hline \multicolumn{3}{|c|}{ Sobel Test $(z)\left(z=4,62^{* * *} ; p<0,001\right)$} \\
\hline \multicolumn{3}{|c|}{ Bağımlı (İş Performansı), Bağımsız (ÖVD), } \\
\hline \multicolumn{3}{|c|}{$\begin{array}{l}{ }^{*} p<0,05,{ }^{* *} p<0,01,{ }^{* * *} p<0,001 \quad N=432 \\
\Delta R^{2}=R^{2} \text { deki değişim, }\end{array}$} \\
\hline
\end{tabular}

Tablo 4: Aşırı Iş̧ Yükünün ÖVD- Işsten Ayrılma Niyeti Arasında Aracılık Rolünü Gösteren Hiyerarşik Regresyon Sonuçları

\begin{tabular}{|c|c|c|}
\hline \multicolumn{3}{|c|}{ ISSTEN AYRILMA NIYETI } \\
\hline \multicolumn{3}{|c|}{ Test 1- İşten Ayrılma Niyeti } \\
\hline & $\beta$ & $\mathrm{t}$ \\
\hline ÖVD & $-0,305^{* * *}$ & $-6,6$ \\
\hline \multicolumn{3}{|c|}{$R 2=0,093$ Düz. $R 2=0,091 \mathrm{~F}=44,10 p(F) 0,000$} \\
\hline \multicolumn{3}{|c|}{ Test 2- Aşırı İş Yükü } \\
\hline & $\beta$ & $\mathrm{t}$ \\
\hline ÖVD & $-0,150^{* *}$ & $-3,2$ \\
\hline \multicolumn{3}{|c|}{$\begin{aligned} \mathrm{R} 2=0,023 \text { Düz. } \mathrm{R} 2=0,020 \mathrm{~F}=9,92 \mathrm{p}(\mathrm{F}) 0,002 \\
\text { AiY } \rightarrow \mathrm{I} \text { AN } b=.450^{* * *}, \mathrm{R} 2=.20\end{aligned}$} \\
\hline \multicolumn{3}{|c|}{ Test 3- İşten Ayrılma Niyeti } \\
\hline & $\beta$ & $\mathrm{t}$ \\
\hline ÖVD & $-0,243^{* * *}$ & $-5,8$ \\
\hline Aşırı İ Yükü & $0,413^{* * *}$ & 9,83 \\
\hline \multicolumn{3}{|c|}{$\begin{array}{c}\mathrm{R} 2=0,260 \Delta R 2=0,167 \text { Düz. R2 }=0,256 \\
F=60,05 p(F)=0,000\end{array}$} \\
\hline \multicolumn{3}{|c|}{ Sobel Test $(z) \quad(z=-3,49 * * * ; p<0,001)$} \\
\hline \multicolumn{3}{|c|}{$\begin{array}{c}\text { Bağımlı (İsten Ayrılma Niyeti), Bağımsız (ÖVD) } \\
{ }^{*} p<0,05,{ }^{* *} p<0,01,{ }^{* * * *} p<0,001 \\
\Delta R 2=R 2^{\prime} \text { deki değişim, } N=432\end{array}$} \\
\hline
\end{tabular}


ÖVD'nin IAN üzerine etkisinde AiY'nin aracılığını test etmek maksadıyla yapılan hiyerarşik regresyon analizinin ilk adımında, ÖVD'nin İAN'yi negatif ve anlamlı olarak etkilediği görülmüştür( $\beta=-0,305 ; p<, 001)$ (Tablo-4). İkinci adımında ÖVD'nin aracılığı araştııılan AiY'ye olan etkisi araştırılmıştır. Analiz sonucunda ÖVD'nin AiY' de negatif ve anlamlı olarak etkilediği $(\beta=-0,150 ; p<, 01)$ tespit edilmiştir. Bu adımda aracılığı araştırılan Aî'nnin IAN' ye olan etkilerine de bakılarak Tablo-4'te rapor edilmiştir $(\beta=, 450 ; p<, 01)$. Analizin üçüncü aşamasında, ÖVD'nin AiY ile birlikte analize sokulmasıyla R2 artmış $(\triangle R 2=0,167)$ ve ilk aşamada var olan ÖVD'nin IAN üzerindeki etkisi azalmıştır $(\beta=-0,243 ; p<, 001)$. Sobel testi sonuçları da aracılık etkisinin anlamlı olduğunu göstermektedir $(z=-3,49 ; p<0,001)$. Bu bulgular ÖVD'nin IAN'ne etkisinde AiY' nin kısmi aracllık rolünün olduğunu göstermektedir (Tablo-4). Bu analiz sonucunda $\mathrm{H} 2$, H5, H7'nin desteklendiği görülmektedir.

\section{TARTIŞMA VE SONUÇ}

Örgütsel vatandaşlık davranışının iş performansı ve işten ayrılma niyeti üzerine etkisi ve bu etkide aşırı iş yükünün aracılık etkisinin olup olmadığı belirlemeye yönelik olarak turizm sektöründe çalışanlar üzerinde yapılan bu araştırmada önemli bulgulara ulaşılmıştır.

Çalışanların sergiledikleri ÖVD’nin iş performansını artıracağına ve işten ayrılma niyetlerini düşüreceğine yönelik hipotezler doğrulanmıştır. Bu konuda elde edilen bulgular kurama ve görgül araştırmalara uygundur (Bateman ve Organ, 1983; Nielsen vd., 2010; Ozdeveicoğlu, 2003; Rosen vd.,2009; Organ,1988; Tanova, 2010). Fakat kendi rollerinin ötesinde ÖVD sergileyen çalışanların belli bir zaman sonra dayanma güçlerinin azalacağı ve bu kişilerin aşırı iş yükü algısı içerisine gireceklerine yönelik hipotez doğrulanmamıştır. Bunda çaış̧anların önemli bir kısmının genç (\% 74'ü 35 yaş altı) ve mevsimlik iş̧̧i (\%77) olmalarının etkisi olabileceği düşünülmektedir. Ayrıca, bu sonuç çok fazla niteliği olmayan ( \% 82'si lise ve altı eğitim seviyesinde) ve işveren tarafından kolaylıkla iş aktinin fesh edilebileceğini düşünen turizm sektörü çalışanlarının işe tutunmak ve gelirlerini devam ettirebilmek için ellerinden geleni yapmaya çalıştıklarının da bir göstergesi olabilir (Günel, 2009:204).

Çalışanların aşırı iş yükü algılarının iş performanslarını düşüreceği ve işten ayrılma niyetleri artıracağına yönelik hipotezler de doğrulanmıştır (Jones vd., 2007; Golden ve Jorgensen, 2002). Dolayısıyla farklı istihdam özellikleri olan turizm sektöründe de çalışanlara kapasitelerinin üzerindeki yüklenmelerin, iş performansının düşmesi ve işten ayrılma niyetinin artması gibi olumsuz sonuçlara sebep olabileceği görülmüştür.
Araştırmanın en önemli bulgusu aşırı iş yükünün aracılığına yönelik elde edilen bulgulardır. Çalışanların aşırı iş yükü algılarının iş performansları ile ÖVD arasındaki ilişkiye aracılık etmediği sobel testi sonucunda görülmüştür. Bu beklenen bir durum değildir. Zira aşırı iş yükü algısı içerisine giren kişiler işlerine tatmin duymayacaklarına (Karatepe vd., 2006; Scott vd.,2006) veya bir kısım işlerini yetiştiremeyebileceklerine inanılmaktadır. Fakat turizm sektöründe çoğu mevsimlik olarak görev yapan ve enerjileri yüksek gençlerden oluşan çalışanların durumlarının beklentilerden farklı bir sonucun ortaya çıkmasına sebep olduğu düşünülmektedir.

ÖVD'nin işten ayrılma niyeti üzerine etkisinde aşırı iş yükünün aracılığı olup olmadığını belirlemeye yönelik yapılan hiyerarşik regresyon analizi sonucunda kısmi aracılık etkisi belirlenmiştir. Dolayısıyla aşırı iş yükü algısı içerisinde olan çalışanların belki performansları çok fazla değişmemekte ama onların işlerinden ayrılarak başka iş bulma istekleri artmaktadır. Bu durum işten atılma ve kısa sürede yeni bir iş bulamama korkusuyla devam bağlıı̆ı gösteren çalışanların performanslarını düşüremedikleri ancak yeni bir iş arayışına da girebildiklerini göstermektedir.

Bu araştırma, işlerin en yoğun olduğu yaz döneminde beş yıldızlı otel ve tatil köylerinde çalışanlar üzerinde yapılmıştır. Araştırmanın sadece önemli bir kısmı genç ve mevsimlik olarak çalışan turizm sektörü çalışanları üzerinde yapılmış olması, önemli bir kısıtdır. Farklı sektörlerde veya farklı ölçekteki işletmelerde yapılacak araştırmaların özellikle aşırı iş yükünün aracılığına ilişkin farklı sonuçlar verebileceği düşünülmektedir. Ayrıca araştırmada kullanılan verilerin sadece Antalya bölgesinden birbirine yakın kültürel özellikler gösteren kişilerden toplanması da araştırmanın diğer bir kısıtıdır. Farklı kültürel özellikler taşıyan işgörenlerden toplanacak verilerin de önemli sonuçlar verebileceği değerlendirilmektedir.

Yapılan çalışma ile özellikle aşırı iş yükünün ÖVD'nin işten ayrılma niyeti üzerine olan olumlu etkilerini düşürebileceğine yönelik elde edilen bulguların literatüre önemli katkı sağladığına inanılmaktadır. ÖVD konusunda araştırma yapanların olaya bir de farklı pencereden bakmalarını ve madalyonun arka yüzünün de olabileceğini düşünmeleri konusunda farkındalık yaratılması, araştırmanın önemli bir sonucudur. Ayrıca uygulayıcıların çalışanların bir kapasitelerinin olduğu, bu kapasitenin zorlanması durumunda kalifiye işgücü dâhil çalışanların işlerinden ayrılmayı düşünebilecekleri konusunda dikkatlerinin çekilmesinin de önemli sonuç olduğuna inanılmaktadır. 


\section{SON NOTLAR}

${ }^{1}$ Bu çalışma Kara Harp Okulu Savunma Bilimleri Enstitüsü Sistem Yönetim Bilimleri programında tamamlanan "Örgütsel Vatandaşlık Davranışı ve Ardılları" başlıklı yüksek lisans tezinden türetilmiştir

\section{KAYNAKLAR}

Allen, T. D. ve Rush M. C. (1998) "The Effects of Organizational Citizenship Behavior on Performance Judgments: A Field Study and A Laboratory Experiment" Journal of Applied Psychology, 83: 247-260.

Barnard, C.I. (1938) The Functions of the Executive, Cambridge, MA Harvard University Press.

Baron, R. M. ve Kenny D. A. (1986) "The Moderator Mediator Variable Distinction in Social Psychological Research: Conceptual, Strategic, and Statistical Considerations" Journal of Personality and Social Psychology, 51: 1173-1182.

Bartlett, K.R. (1999) "The Relationship Between Training and Organizational Commitment in the Health Care Field" The Degree of Doctor of Philosophy, Urbana, The University of Illinois,.

Bateman, T. S. ve Organ D. W. (1983) "Job Satisfaction and the Good Soldier: The Relationship Between Affect and Employee Citizenship" Academy of Management Journal, 26(4): 587-595.

Bellou, V. (2008) "Exploring Civic Virtue and Turnover Intention During Organizational Changes" Journal of Business Research, 61: 778-789.

Blau, P. (1964) Exchange and Power in Social Life, New York, John Wiley \& Sons.

Bolino, M.C. ve Turnley W.H. (2005) "The Personal Costs of Citizenship Behavior: The Relationship Between Individual Initiative and Role Overload, Job Stress, and Workfamily Conflict" Journal of Applied Psychology, 90(4):740-748.

Bolino, M.C., Turnley W.H. ve Niheoff B.P. (2004) "The Other Side of the Story: Reexamining Prevailing Assumptions About Organizational Citizenship Behavior" Human Resource Management Review, 14:229246.

Borman, W.C., White L.A. ve Dorsey D.W. (1995) "Effects of Ratee Task Performance and Interpersonal Factors on Supervisor and Peer Performance Ratings" Journal of Applied Psychology , 80(1):168-77.

Borman, W. C. ve Motowidlo S.J. (1993) "Expanding the Criterion Domain Include Elements of Contextual Performance" Schmitt, et al (eds), Personnel Selection in Organization, San Francisco, Jossey-Bass.
Borman, W. C. ve Motowidlo S.J. (1997) "Introduction: Organizational Citizenship Behavior and Contextual Performance" Human Performance, 10: 67-69.

Byrne, Z.S. (2005) "Fairness Reduces the Negative Effects of Organizational Politics on Turnover Intentions, Citizenship Behavior and Job Performance" Journal of Business and Psychology, 20(2):175-200.

Chughtai, A.A. ve Zafar S. (2006) "Antecedents and Consequences of Organizational Commitment Among Pakistani University Teachers" Applied H.R.M. Research, 11(1): 39-64.

Cropanzano, R. ve Byrne Z. S. (2003) "The Relationship of Emotional Exhaustion to Work Attitudes, Job Performance Ratings, and Organizational Citizenship Behaviors" Journal of Applied Psychology, 88(1): 160-169.

Çöl, G. (2008) "Algılanan Güçlendirmenin İs Gören Performansı Üzerine Etkileri” Doğuş Üniversitesi Dergisi, 9(1):35-46.

Demir, M. ve Tütüncü, Ö. (2010) "Ağırlama İşletmelerinde Örgütsel Sapma ile İşten Ayrılma Eğilimi Arasındaki İlişki” Anatolia: Turizm Araştırmaları Dergisi, 21(1):64-74.

Derya, S. (2008) "Crossover of Work-Family Conflict: Antecedent and Consequences of Crossover Process in Dual-Earner Couples" Yayımlanmamış Doktora Tezi, İstanbul, Koç Üniversitesi.

Elloy, D.F. ve Smith C.R. (2003) "Patterns of Stress Work-Family Conflict, Role Conflict, Role Ambiguity and Overload Among Dual-Career and Single Career Couples: An Australian Study" Cross Cultural Management, 10(1):55-66.

Felfe, J., Yan W. ve Six B. (2008) "The Impact of Individual Collectivism on Commitment and Its Influence on Organizational Citizenship Behaviour and Turnover in Three Countries" International Journal of Cross Cultural Management, 8(2): 211-237.

Fox, S. ve Spector P.E. (2009) "The Deviant Citizen: Clarifying the Measurement of OCB And Its Relation to CWB" http://www.personal.psu.edu/ krm10/ PSY597SP07/Week\%205\%20readings/fox\%20and\%20 spector.pdf, (02.03.2011). 
Golden, L. ve Jorgensen H. (2002) "Time After Time Mandatory Overtime in the U.S. Economy" Economic Policy, Institute Briefing Paper, http://www.epi.org/ publication/briefingpapers_bp120/, (07.03.2011).

Gouldner, A. W. (1960) "The Norm of Reciprocity: A Preliminary Statement" American Sociological Review, 25 (2): 161-178.

Greenhaus, J.H., Parasuraman S., Granrose C.S., Rabinowitz S. ve Beutell N.J. (1989) "Sources of WorkFamily Conflict Among Two Career Couples” J. Vocational Behaviour, 34: 133-153.

Günel, Ö. D. (2009) "Mevsimsellik, Mevsimlik İstihdam ve Örgütsel Bağllılı: Konaklama İşletmelerinde Bir Araştırma” Dokuz Eylül Üniversitesi Işletme Fakültesi Dergisi, 10(2): 199-219.

Jones, E., Chonko L., Rangarajan D. ve Roberts J. (2007) "The Role of Overload on Job Attitudes, Turnover Intentions, and Salesperson Performance" Journal of Business Research, 60: 663-671.

Kamer, M. (2001) "Örgütsel Güven, Örgütsel Bağlılık ve Örgütsel Vatandaşlık Davranışlarına Etkileri” Yayınlanmamış Yüksek Lisans Tezi, İstanbul, Marmara Üniversitesi Sosyal Bilimler Enstitüsü.

Karatepe, O.M., Uladag O., Menevis I., Hadzimehmedagic L. ve Baddar L. (2006) "The Effects of Selected Individual Characteristics on Frontline Employee Performance and Job Satisfaction" Journal of Tourism Management, 27: 547-560.

Khalid, S.A ve Hassan A. (2005) "The Effects of Organizational Citizenship Behaviour on Withdrawal Behaviour: A Malaysian Study" International Journal of Management and Entrepreneurship, 1(1):30- 40.

Kirkman, B. L. ve Rosen B. (1999) "Beyond SelfManagement: Antecedents and Consequences of Team Empowerment" Academy of Management Journal, 42(1): 58-74.

Lowery, C. M. ve Krilowicz T. J. (1994) "Relationships Among Nontask Behaviors, Rated Performance, and Objective Performance Measures" Psychological Reports, 74: 571-578.

Luk, D. M. ve Shaffer M. A. (2005) "Work and Family Domain Stressors and Support: Direct and Indirect Influences on Work-Family Conflict"Journal of Occupational and Organisational Psychology, 78: 489-508.

MacKenzie, S. B., Podsakoff P. M. ve Fetter R. (1993) "The Impact of Organizational Citizenship Behavior on Evaluations of Sales Performance" Journal of Marketing, 57: 70-80.
Nadiri, H. ve Tanova C. (2010) "An Investigation of the Role of Justice in Turnover Intentions, Job Satisfaction, and Organizational Citizenship Behavior in Hospitality Industry" International Journal of Hospitality Management, 29: 33-41.

Netemeyer, R.G., Boles J.S., Mckee D.O. ve Mcmurrian R. (1997) "An Investigation Into the Antecedents of Organizational Citizenship Behaviors in A Personnel Selling Context" Journal of Marketing, 61(3): 85-98.

Nielsen, T.M., Bachrach D.G., Sundstrom E. ve Halfhill T.R.(2012) "Utility of OCB: Organizational Citizenship Behavior and Group Performance in a Resource Allocation Framework" Journal of Management, 38(2):1-27.

Ok, A.B. (2007) "Kuruma Bağlılığın İlişkili Olduğu Değişkenler: Kurumsal İletişime Özel Bir Vurgu" Yayımlanmamış Doktora Tezi, Ankara, ODTÜ Psikoloji Bölümü.

Organ D. W. (1988) Organizational Citizenship Behavior: The Good Soldier Syndrome, Lexington, MA Lexington Books.

Organ, D.W. (1990a) "The Motivational Basis of Organizational Citizenship Behavior" Staw et al (eds.) Research in Organizational Behavior, 12:43-72. Greenwich, CT JAI Press.

Organ, D.W. (1990b) "The Subtle Significance of Job Satisfaction" Clinical Laboratory Management Review, 4: 94-98.

Organ, D.W. ve Ryan K. (1995) "A Meta-Analytic Review of Attitudinal and Dispositional Predictors of Organizational Citizenship Behavior" Personel Psychology, 48: 775-802.

Özdevecioğlu, M. (2003) "ÖVD ile Üniversite Öğrencilerinin Bazı Demografik Özellikleri ve Akademik Başarıları Arasındaki İlişkilerin Belirlenmesine Yönelik Bir Araştırma” Erciyes Üniversitesi İktisadi ve İdari Bilimler Fakültesi Dergisi, 20:117-135.

Peterson, M. F., Smith P. B, Akande A. ve Ayestaran S. (1995) "Role Conflict, Ambiguity, and Overload: A 21-Nation Study" Academy of Management Journal, 38: 429-452.

Podsakoff, P.M. ve Mackenzie S.B. (1997) "Impact of Organizational Citizenship Behavior on Organizational Performance: A Review and Suggestions for Future Research" Human Performance, 10(2): 133-151. 
Podsakoff, P. M., Mackenzie S. B., Paine J. B. ve Bachrach D. G. (2000) "Organizational Citizenship Behaviors: A Critical Review of the Theoretical and Empirical Literature and Suggestions for Future Research" Journal of Management, 26(3):513-563.

Redman, T. ve Snape E. (2005) "I to Wed: The Role of Consciousness Transformation in Compassion and Altruism" Journal of Management Studies, 42(2): 915932.

Rosen, C.C., Harris K.J. ve Kacmar K.M. (2009) "The Emotional Implications of Organizational Politics: A Process Model" Human Relations, 62(1):27-57.

Schepman, S.B. ve Zarate M.A. (2008) "The Relationship Between Burnout, Negative Affectivity and Organizational Citizenship Behavior for Human Services Employees" International Journal of Human and Social Sciences, 2(4):216-221.

Schnake, M. ve Dumler M. P. (1993) "The Relationship Between Traditional Leadership, Super Leadership and Organizational Citizenship Behavior" Group and Organizational Management, 18(3):352-366.

Scott, A., Gravelle H., Simoens S., Bojke C. ve Sibbald B. (2006) "Job Satisfaction and Quitting Intentions: A Structural Model of British General Practitioners" British Journal of Industrial Relations, 44(3):519-540.

Sigler, T.H. ve Pearson C. M. (2000) "Creating An Empowering Culture: Examining the Relationship Between Organizational Culture and Perceptions of Empowerment" Journal of Quality Management, 5:27-52.

Singh, A.K. ve Singh A.P. (2008) "Personal Outcomes of Organizational Citizenship Behavior" ASBM Journal of Management, 1(1):47-56.

Spector, P.E., Fox S., Miles D.E. ve Borman W.E. (2002) "Building An Integrative Model of Extra Role Work Behaviors: A Comparison of Counterproductive Work Behavior With Organizational Citizenship Behavior" International Journal of Selection And Assessment, 10(1/2):51-57.
Spitzmuller, M., Van Dyne L. ve Ilies R. (2008) "Organizational Citizenship Behavior: A Review and Extension of Its Nomological Network" Paper Series No: 5124.

Suazo, M.M., Turnley W.H. ve Mai R.R. (2005) “The Role of Perceived Violation in Determining Employees' Reactions to Psychological Contract Breach" Journal of Leadership and Organizational Studies, 12(1):24-36.

Şeşen, H. (2008) "Örgütsel Vatandaşlık Davranışı Çalışmaları Üzerine Eleştirel Bir Çözümleme: Teleolojik ve Epistemolojik Kaygilar" KHO SAVBEN Dergisi, 7(2):57-86.

Vey, M.A. ve Campel J.P. (2004) "In-role or ExtraRole Organizational Citizenship Behavior: Which Are We Measuring?" Human Performance, 17(1):119-135.

Walsh, J. P., Ashford S. J., ve Hill T. E. (1985) "Feedback Obstruction: The Influence of the Information Environment on Employee Turnover Intention" Human Relations, 38(1):23-46.

Wegge J., Van Dick R., Fisher G. K., Wecking C. ve Moltzen K. (2006) "Work Motivation, Organizational Identification, and Well-Being in Call Centre Work" WorkÆStress, 20(1): 60-83.

William, S. ve Shiaw W. T. (1999) "Mood and Organizational Citizenship Behavior: The Effects of Ositive Affect on Employee" Journal of Psycology, 133(6): 656-669.

Williams, L. J. ve Anderson S. E. (1991) "Job Satisfaction and Organizational Commitment as Predictors of Organizational Citizenship and In-Role Behaviors" Journal of Management, 17(3): 601-617. 